\begin{tabular}{|l|l|l||}
\hline \multicolumn{2}{|c|}{ PublisherInfo } \\
\hline \hline PublisherName & $:$ & BioMed Central \\
\hline \hline PublisherLocation & $:$ & London \\
\hline \hline PublisherImprintName & $:$ & BioMed Central \\
\hline \hline
\end{tabular}

\title{
Raloxifene and breast cancer risk
}

\begin{tabular}{|l|l|l||}
\hline \multicolumn{2}{|c||}{ ArticleInfo } \\
\hline \hline ArticleID & $:$ & 3610 \\
\hline \hline ArticleDOI & $:$ & $10.1186 /$ bcr-1999-66588 \\
\hline \hline ArticleCitationID & $:$ & 66588 \\
\hline \hline ArticleSequenceNumber & $:$ & 30 \\
\hline \hline ArticleCategory & $:$ & Paper Report \\
\hline \hline ArticleFirstPage & $:$ & 1 \\
\hline \hline ArticleLastPage & $:$ & 4 \\
\hline \hline & & RegistrationDate : 1999-6-29 \\
\hline ArticleHistory & $:$ & OnlineDate \\
\hline \hline ArticleCopyright & $:$ & Current Science Ltd1999-6-29 \\
\hline \hline ArticleGrants & $:$ & \\
\hline \hline ArticleContext & $:$ & 1305811 \\
\hline \hline
\end{tabular}




\section{Keywords}

breast cancer, selective estrogen receptor modulator, raloxifene, venous thromboembolism, endometrial cancer

\section{Introduction}

Raloxifene hydrochloride is a selective estrogen receptor (ER) modulator which is used in the treatment of osteoporosis. Due to its relationship with tamoxifen and the results of previous studies, it has been hypothesised that raloxifene might prevent breast cancer. Larger scale randomised evidence regarding the effect of raloxifene on adverse outcomes such as venous thromboembolism and endometrial hyperplasia/carcinoma is also important in guiding clinical use.

\section{Aims}

To determine whether women taking raloxifene have a lower risk of invasive breast cancer than nonusers and to assess the safety of treatment with raloxifene.

\section{Comments}

Evidence regarding selective estrogen receptor modulators such as raloxifene has aroused considerable interest at the prospect of being able to treat osteoporosis without increasing the risk of breast cancer (in contrast to hormone replacement therapy). The MORE trial was designed to detect relevant changes in the primary end point of fracture, and is not necessarily large enough to detect changes in less common but clinically important end points such as endometrial cancer. The findings regarding breast cancer are reassuring and encouraging, although based on relatively small numbers of cases. The findings regarding endometrial thickness are cause for concern and an increase in the risk of endometrial cancer cannot be excluded on the basis of this trial. The increased risk of venous thromboembolism, and symptoms such as hot flushes, should also be considered when evaluating the risks and benefits of treatment with raloxifene. 


\section{Methods}

The Multiple Outcomes of Raloxifene Evaluation (MORE) study is a randomised placebo-controlled double-blind clinical trial involving 180 clinical centers in 25 countries, mainly in the United States and Europe. Eligible women were postmenopausal, younger than 81 years (mean age 66.5), with osteoporosis, defined by the presence of vertebral fractures or a femoral neck or spine T-score of at least 2.5 standard deviations below the mean for young healthy women. Potential participants underwent breast examination and mammography (or breast ultrasonography if they refused mammography). Women with a history of breast cancer, invasive endometrial cancer, abnormal uterine bleeding, stroke or venous thromboembolic disease in the past 10 years or taking estrogen were excluded. A total of 7705 women were randomised over the period of 1994 to 1998 to receive $120 \mathrm{mg}$ raloxifene per day, $60 \mathrm{mg}$ raloxifene per day or placebo. All participants received daily supplements of $500 \mathrm{mg}$ of calcium and 400-600 IU cholecalciferol.Participants were followed up every 6 months for incident morbidity and adverse events, including diagnoses such as breast cancer, endometrial cancer and venous thromboembolism. Mammographic screenings were optional after the first year but were mandatory after 2 years and after 3 years of treatment. A total of 1936 women had transvaginal ultrasound at baseline to assess endometrial status and of these women, 1781 had at least one follow-up sonogram. Patient reports of breast cancer and endometrial cancer were confirmed using review of histopathology and medical records by study specialists who were blinded to treatment assignation, all reported cases of venous thromboembolism were included as the relevant panel had not completed their adjudication. Analyses were on the basis of intention-to-treat.

\section{Results}

Overall, 2572 women were assigned to $120 \mathrm{mg}$ /day raloxifene, 2557 to $60 \mathrm{mg} /$ day raloxifene and 2576 to placebo. There were no significant differences at baseline between the characteristics of women in each group. Median length of follow up was 40 months (standard deviation 3 years) and a total of $1152(22 \%)$ and $652(25 \%)$ women had withdrawn from the raloxifene and placebo arms, respectively, by 36 months.A total of 54 new cases of breast cancer (invasive and non-invasive types combined) were diagnosed in study participants; 22 in the 5129 women assigned to raloxifene and 32 in the 2576 assigned to placebo (relative risk [RR], 0.35; 95\% confidence interval [CI], 0.21-0.58). A total of 40 new cases of invasive breast cancer were diagnosed; 13 in those assigned to raloxifene and 27 in those assigned to placebo (RR, 0.24; 95\% CI, 0.13-0.44). Raloxifene was associated with a significantly lower risk of ER positive invasive breast cancer ( RR, 0.10; 95\% CI, 0.04-0.24) but did not have the same effect on ER negative disease (RR, 0.88; 95\% CI, 0.26-3.00). Effects were similar according to dose of raloxifene.There were 49 cases of thromboembolic disease in the raloxifene arm of the trial and 8 cases in the placebo arm (RR, 3.1; 95\% CI, 1.5-6.2). In women who had undergone ultrasound examination, raloxifene treatment was associated with an increased endometrial thickness compared to placebo $(\mathrm{P}<$ 0.01). No overall increase in the risk of endometrial cancer was seen, although the numbers involved were small. Hot flushes (flashes), influenza-like syndromes, endometrial cavity fluid, peripheral edema, leg cramps and diabetes were all reported significantly more frequently in the raloxifene compared to the placebo group. Hypertension, hypercholesterolamia, hematuria and bradycardia were all reported 
significantly less frequently in the raloxifene group. Overall mortality did not differ between the placebo $(1.0 \%)$ and combined raloxifene group $(0.8 \%)$.

\section{Discussion}

Raloxifene reduced the risk of newly diagnosed invasive breast cancer by $76 \%$ during a median of 40 months of treating postmenopausal women for osteoporosis. This appeared to be due to its effect on ER positive tumors and is in keeping with an hypothesised inhibitory effect of raloxifene on oestrogeninduced DNA transcription. Since breast cancer generally requires several years to grow to a clinically or radiologically detectable size, the majority of tumors diagnosed during this trial were probably present before the trial began. Any effect of raloxifene is therefore likely to represent suppression or regression of subclinical cancer. Raloxifene may reduce the risk of breast cancer more substantially than tamoxifen, however it is difficult to make comparisons based on the available trial data. Endometrial thickness was significantly increased in women on raloxifene, but it is difficult to comment on its effect on endometrial cancer or hyperplasia given the small numbers of women with these conditions. The authors do not believe that monitoring of the endometrium through ultrasonography or biopsy is warranted in women taking raloxifene. Raloxifene increases the risk of venous thromboembolism and women with a history of venous thrombosis or pulmonary embolism should not take this medication. Women currently taking raloxifene should discontinue use before major surgery or periods of immobilisation. The effect of raloxifene on the risk of heart disease needs further study. Tamoxifen and raloxifene may be useful preventative therapies for women who have an increased risk of ER positive breast cancer and vertebral fractures, however, women with osteoporosis are generally at a reduced risk of breast cancer. Both tamoxifen and raloxifene increase hot flushes.

\section{References}

1. Cummings SR, Eckert S, Krueger KA, Grady D, Powles TJ, Cauley JA, Norton L, Nickelsen T, Bjarnason NH, Morrow M, Lippman ME, Black D, Glusman JE, Costa A, Jordan VC: The effect of raloxifene on risk of breast cancer in postmenopausal women. JAMA. 1999, 281: 2189-2197. 